\title{
Metastatic and synchronous ovarian involvement in low-risk endometrial cancer; clinicopathological analysis with detection of DNA mismatch repair deficiency
}

\author{
Şener Gezer ${ }^{1}$, , Büşra Yaprak Bayrak ${ }^{2}$ (D) \\ ${ }^{1}$ Department of Gynecologic Oncology, Kocaeli University School of Medicine, Umuttepe, Kocaeli, Turkey \\ ${ }^{2}$ Department of Pathology, Kocaeli University School of Medicine, Umuttepe, Kocaeli, Turkey
}

\begin{abstract}
Objectives: This study aimed to investigate ovarian involvement in low-risk endometrial cancer, the associated risk factors, and impact on overall survival. We attempted to explore the differences in mismatch repair (MMR) deficiency between metastatic and synchronous ovarian tumoral involvement.

Material and methods: This was a retrospective study of patients with low-risk endometrial cancer who were treated at a tertiary center between January 2006 and December 2019. The primary outcome measures were the incidence and risk factors associated with metastatic and synchronous tumoral involvement of the ovary. Overall, survival data were also analyzed. Metastatic and synchronous tumors were compared with each other in terms of MMR deficiency with IHC staining.

Results: From a total of 360 low-risk endometrial cancer patients, 10 (2.8\%) had ovarian metastasis and 12 (3.3\%) had synchronous ovarian involvement. The median age of patients with metastasis was significantly lower than that of patients without ovarian involvement ( 49 vs 57 years, $p=0.004$ ). Most patients in the metastatic group were in the $<50$ age group $(p<0.001)$ and premenopausal period $(p=0.001)$. As a result of IHC staining performed on patients with ovarian involvement, MMR deficiency was found in six (60\%) patients in the metastatic group and six (50\%) patients in the synchronous group. No significant difference was found in overall survival between groups.

Conclusions: Younger age and premenopausal status were risk factors associated with ovarian metastasis. Overall survival did not show differences between all groups, and MMR deficiency was similar between metastatic and synchronous groups. Key words: low-risk endometrial cancer; ovarian involvement; ovarian metastasis; synchronous ovarian cancer
\end{abstract}

Ginekologia Polska 2021; 92, 9: 599-606

\section{INTRODUCTION}

Ovarian involvement in endometrial cancer patients can take two forms: metastasis of cancer in the endometrium and synchronous ovarian cancer. In stage I endometrial cancers, ovarian metastases occur in approximately five percent of cases; diagnosis is often confirmed preoperatively, but in some patients, the cancer can only be detected intraoperatively [1]. In the low-risk population (Endometrioid, $<1 / 2$ myometrial invasion, absence of lymphovascular invasion), the incidence is as low as $0.5 \%$ [2]. The incidence of synchronous tumors of the endometrium and ovary ranges from $2-23 \%$ in the literature $[3,4]$.
Deep myometrial invasion, high-grade and non-endometrioid tumor types, lymphovascular invasion, serosal and tubal spread were defined as factors associated with ovarian involvement. Moreover, some studies were performed on stage I patients and most were not carried out on low-risk patient populations [1, 4-6]. It is interesting that a low-grade tumor with no myometrial or lymphovascular invasion can metastasize to the ovary. However, this raises the patient from the low-risk category to stage III. Synchronous tumors, on the other hand, represent a favorable prognosis compared with metastatic tumors $[7,8]$.

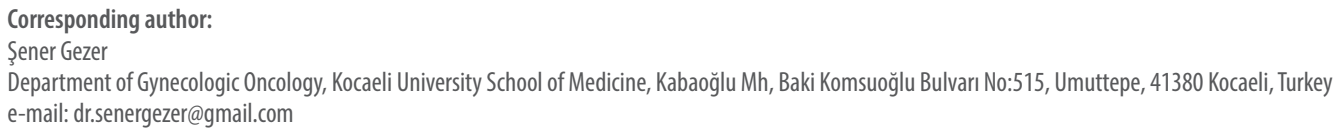


Although only $5-10 \%$ of endometrial cancers with mismatch repair (MMR) deficiency are associated with Lynch syndrome, in fact, $20-40 \%$ of endometrial cancers experience MMR loss [9]. Genomic and immunohistochemical (IHC) studies have attempted to understand the biological behavior of synchronous and metastatic tumors. Although the clinical outcome of synchronous tumors is distinct from that of metastatic tumors, the investigation of MMR loss may give a new dimension to the clinicopathologic criteria we use to separate these tumors $[10,11]$.

It is important to know the frequency of ovarian involvement in endometrial cancer in preoperative counseling, especially if the protection of the ovaries is planned. In this study, we retrospectively analyzed low-risk endometrial cancer cases with ovarian involvement. We aimed to analyze the risk factors associated with metastasis or synchronous tumors and to investigate the impact on overall survival.

\section{MATERIAL AND METHODS}

\section{Patient cohort}

From January 2006 to December 2019, we conducted a retrospective review of patients with endometrial cancer who were treated at a tertiary center. The Institutional Review Board approved the study (KU GOKAEK 2020/6), and all procedures were performed in accordance with the principles of the Declaration of Helsinki. Demographic, clinical and pathologic data were obtained through the hospital's electronic record system and from paper charts. Age, gravidity, parity, Body Mass Index (BMI), menopausal status, systemic diseases, adjuvant therapies, and pathologic variables were noted. We identified patients with concurrent endometrial and ovarian involvement from a low-risk endometrial cancer cohort (endometrioid type, Grade 1 and 2 tumors, less than $1 / 2$ myometrial invasion and without lymphovascular spread). All patients underwent hysterectomy with salpingo-oophorectomy, pelvic, and/or paraaortic lymphadenectomy in accordance with the risk category, inspection of the abdomen, and washing cytology procedures. Adjuvant therapies such as chemotherapy and radiotherapy were individualized for all patients, but no patient received neoadjuvant therapy.

The primary outcome measures were the risk factors associated with metastatic and synchronous tumoral involvement of the ovary. Overall survival data were also obtained from the population registry agency, which gives certain information about the patient's death and minimized lost to follow-up. Metastatic and synchronous tumors were compared with each other in terms of MMR deficiency with IHC staining.

\section{Histopathological examination}

Pathologic specimens were reviewed by experienced gynecologic pathologists. After fixation in 10\% neutralized formaldehyde, all hysterectomy and salpingoophorectomy tissues were cut into 3-mm thick slices for tumor viewing. The materials were completely embedded in paraffin and cut into 5 - $\mu \mathrm{m}$-thick sections. The cut preparations were then dyed with hematoxylin and eosin (H\&E) and examined with a light microscope. The Scully criteria were used to separate synchronous ovarian tumors from ovarian metastases of endometrial cancers [12].

\section{Immunohistochemical examination}

Immunohistochemical staining of DNA-MMR protein expression was performed on endometrial and ovarian samples in blocks fixed with formalin and embedded in paraffin. Representative whole 5- $\mu$ m-thick sections were performed with IHC. Anti-PMS2 (A16-4, 1:200; Ventana Medical Systems, Arizona, USA), anti-MLH1 (M1, 1:200 dilution; Ventana Medical Systems, Arizona, USA), anti-MSH2 (G219-11229, 1:50 dilution, Ventana Medical Systems, Arizona, USA), and anti-MSH6 (SP93, 1:200 dilution; Ventana Medical Systems, Arizona, USA) were evaluated. Tissues were stained with antibodies against PMS2, MSH6, MLH1, and MSH2 following deparaffinization. Slides were counterstained with hematoxylin \& eosin. Complete loss of nuclear staining for at least one MMR protein was defined as MMR deficiency. Stromal and inflammatory cells of the adjacent normal mucosa with intact nuclear staining were used as an internal positive control.

\section{Statistical analysis}

All statistical analyses were performed using IBM SPSS for Windows version 20.0 (SPSS, Chicago, IL, USA). Kolmogorov-Smirnov and Shapiro-Wilk's tests were used to assess the assumption of normality. Categorical variables were summarized as counts (percentages). Continuous variables were presented as the median $\left(25^{\text {th }}-75^{\text {th }}\right.$ percentile) since the normality assumption did not hold. Comparisons of continuous variables between groups were carried out using the Kruskal-Wallis test with Dunn's test for multiple comparisons. Associations between two categorical variables were examined by Chi-square test. Multinomial logistic regression analysis was used to determine the factors affecting the outcome variable. The Kaplan-Meier method was used for the survival analysis, and a univariate log-rank test was used to assess statistical significance. Overall survival was defined as the time from surgery to death from any cause. All statistical analyses were carried out with five percent significance and a two-sided $p$ value $<0.05$ was considered as statistically significant.

\section{RESULTS}

Our patient population consisted of a total of 360 patients with low-risk endometrial cancer, of which 10 (2.8\%) 


\begin{tabular}{|c|c|c|c|c|c|}
\hline & & \multicolumn{3}{|c|}{ Ovarian involvement } & \multirow{2}{*}{$\mathbf{p}$} \\
\hline & & None $(n=338)$ & Metastasis $(n=10)$ & Synchronous $(n=12)$ & \\
\hline \multicolumn{2}{|l|}{ Age } & $57(24-82)^{a}$ & $49(42-58)^{a}$ & $53(42-69)$ & 0.003 \\
\hline \multirow{2}{*}{ Age group } & $<50$ & $71(21)^{\mathrm{a}}$ & $8(80)^{a}$ & $4(33)$ & \multirow{2}{*}{$<0.001$} \\
\hline & $>50$ & $267(79)^{\mathrm{a}}$ & $2(20)^{a}$ & $8(67)$ & \\
\hline \multicolumn{2}{|l|}{ Gravida } & $3(0-16)$ & $3(0-7)$ & $3(0-6)$ & 0.471 \\
\hline \multicolumn{2}{|l|}{ Parity } & $3(0-13)$ & $2(0-4)$ & $3(0-4)$ & 0.405 \\
\hline \multicolumn{2}{|l|}{ BMI } & $28(27-29)$ & $28.1(27-29)$ & $27.8(26-29)$ & 0.919 \\
\hline \multirow{2}{*}{ Menopause } & Pre & $74(22)^{\mathrm{a}}$ & $7(70)^{a}$ & $6(50)$ & \multirow{2}{*}{0.001} \\
\hline & Post & $264(78)^{a}$ & $3(30)^{a}$ & $6(50)$ & \\
\hline \multicolumn{2}{|c|}{ Hypertension } & $163(48)$ & $2(20)$ & $5(42)$ & 0.185 \\
\hline \multicolumn{2}{|l|}{ Diabetes } & $88(26)$ & $1(10)$ & $1(8)$ & 0.232 \\
\hline \multirow{2}{*}{ Grade } & 1 & $223(66)$ & $4(40)$ & $10(83)$ & \multirow{2}{*}{0.093} \\
\hline & $\|$ & $115(34)$ & $6(60)$ & $2(17)$ & \\
\hline \multicolumn{2}{|c|}{ Tumor diameter $(\mathrm{cm})$} & $2.5(0.1-9)$ & $2.5(1.5-6)$ & $2.5(0.5-6)$ & 0.876 \\
\hline \multicolumn{2}{|c|}{ The longest diameter of ovarian mass $(\mathrm{cm})$} & & $3(2-8)$ & $6.7(0.4-15)$ & 0.470 \\
\hline \multicolumn{2}{|c|}{ Lymphadenectomy } & $69(20)^{b}$ & $5(50)$ & $8(67)^{b}$ & 0.001 \\
\hline \multicolumn{2}{|c|}{ Excised pelvic lymph node count } & $13(0-44)$ & $13(0-35)$ & $16(0-29)$ & 0.371 \\
\hline \multicolumn{2}{|c|}{ Patients with pelvic lymph node metastasis } & $3(1)$ & - & - & \\
\hline \multicolumn{2}{|c|}{ Excised paraaortic lymph node count } & $0(0-19)^{b}$ & $0(0-10)$ & $0(0-9)^{b}$ & 0.001 \\
\hline \multicolumn{2}{|c|}{ Patients with paraaortic lymph node metastasis } & $1(0.3)$ & $1(10)$ & $1(8)$ & \\
\hline \multicolumn{2}{|c|}{ Excised total lymph node count } & $14(0-55)$ & $17(0-35)$ & $18(0-34)$ & 0.158 \\
\hline \multicolumn{2}{|c|}{ Total patients with lymph node metastasis } & $4(1.2)$ & $1(10)$ & $1(8)$ & \\
\hline \multicolumn{2}{|c|}{ Total metastatic lymph node count } & $0(0-2)^{a}$ & $0(0-1)^{\mathrm{a}}$ & $0(0-1)$ & 0.006 \\
\hline \multicolumn{2}{|c|}{ Chemotherapy } & $7(2)^{a b}$ & $4(40)^{a}$ & $7(58)^{b}$ & $<0.001$ \\
\hline \multicolumn{2}{|l|}{ Radiotherapy } & $15(4)$ & $2(20)$ & $2(17)$ & 0.041 \\
\hline
\end{tabular}

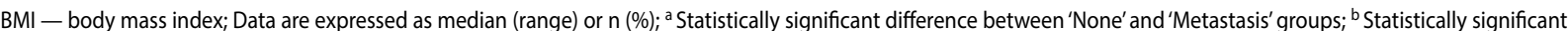
difference between 'None' and 'Synchronous' groups

had ovarian metastasis of the endometrium, and 12 (3.3\%) had synchronous ovarian involvement of the endometrium and ovary. The median follow-up time was 74.5 months (Range: 6-167). Table 1 summarizes the clinicopathologic variables by group. The median age of patients with metastasis was significantly lower than that of patients without ovarian involvement (49 vs 57 years, $p=0.004$ ). Most patients in the metastatic group were in the $<50$ age group $(p<0.001)$ when patient age was divided into subgroups below and above 50 years. Furthermore, most of the metastatic patients were in the premenopausal period $(p=0.001)$.

Patients in the synchronous group had significantly more lymphadenectomy than those in the non-involvement group ( $p<0.001$ ). Although there was no difference in total and metastatic pelvic lymph node number among the groups, the number of excised paraaortic lymph nodes in the synchronous group was greater compared with the non-involvement group $(p=0.001)$. The total metastatic lymph node count was significantly higher in the metastatic group than in the non-involvement group ( $p=0.047$ ). In the case of ovarian involvement with metastasis or synchronous tumor, adjuvant chemotherapy $(\mathrm{p}<0.001)$ and radiotherapy $(p=0.041)$ were used significantly more often in the treatment protocol.

Multinomial logistic regression analysis for ovarian involvement identified that people $<50$ years old were 16.1 times more likely to be in the metastasis group than those $>50$ years old (Tab. 2). Patients with Grade 1 tumors were $1 / 0.17=5.88$ times less likely to be in the metastasis group than those with Grade 2 tumors. Postmenopausal patients were $1 / 0.13=7.69$ times less likely to be in the synchronous group than premenopausal patients. Patients without lymphadenectomy were $1 / 0.08=12.5$ times less likely to be in the synchronous group than those with lymphadenectomy.

As a result of IHC staining performed on patients with ovarian involvement, MMR deficiency was found in six (60\%) patients in the metastatic group and six (50\%) patients in 
Table 2. Multinomial logistic regression analysis for ovarian involvement

\begin{tabular}{|c|c|c|c|}
\hline \multicolumn{2}{|c|}{ Ovarian involvement ${ }^{*}$} & \multirow[t]{2}{*}{ OR $(95 \% \mathrm{Cl})$} & \multirow{2}{*}{$\begin{array}{c}\mathbf{p} \\
0.020\end{array}$} \\
\hline \multirow{13}{*}{ Metastasis } & Intercept & & \\
\hline & Tumor diameter & $0.87(0.55-1.39)$ & 0.573 \\
\hline & Age & & \\
\hline & $\leq 50$ & $16.10(1.81-143.25)$ & 0.013 \\
\hline & $>50$ & 1.00 (reference) & \\
\hline & Menopause & & \\
\hline & Post & $0.65(0.09-4.75)$ & 0.672 \\
\hline & Pre & 1.00 (reference) & \\
\hline & Grade & & \\
\hline & I & $0.17(0.04-0.73)$ & 0.017 \\
\hline & ॥ & 1.00 (reference) & \\
\hline & Lymphadenectomy & & \\
\hline & $\begin{array}{l}\text { No } \\
\text { Yes }\end{array}$ & $\begin{array}{c}0.17 \text { (0.002-1.65) } \\
1.00 \text { (reference) }\end{array}$ & 0.125 \\
\hline \multirow{13}{*}{ Synchron } & Intercept & & 0.004 \\
\hline & Tumor diameter & $1.22(0.85-1.75)$ & 0.275 \\
\hline & Age & & \\
\hline & $\leq 50$ & $0.31(0.05-1.87)$ & 0.202 \\
\hline & $>50$ & 1.00 (reference) & \\
\hline & Menopause & & \\
\hline & Post & $0.13(0.02-0.68)$ & 0.016 \\
\hline & Pre & 1.00 (reference) & \\
\hline & Grade & & \\
\hline & 1 & $3.33(0.63-17.70)$ & 0.157 \\
\hline & II & 1.00 (reference) & \\
\hline & Lymphadenectomy & & \\
\hline & $\begin{array}{l}\text { No } \\
\text { Yes }\end{array}$ & $\begin{array}{l}0.08(0.01-0.68) \\
1.00 \text { (reference) }\end{array}$ & 0.021 \\
\hline
\end{tabular}

"The reference category is 'None'; $\mathrm{OR}$ — odds ratio; $\mathrm{Cl}$ — confidence interval the synchronous group. All tumors had the same MMR protein expression status both endometrial and ovarian specimens. Immunohistochemical staining and survey results for metastatic and synchronous tumors are indicated in Tables 3 and 4. The mean age of patients with MMR deficiency was higher than MMR proficient patients (62 vs 51), while the number of premenopausal patients was similar (7/12 vs 7/10). MMR deficient tumors were more likely to be at higher grade when compared to MMR proficient tumors (9/12 vs 3/12).

The average survival was calculated as 144 months (Standard Error [SE]: 3.093, 95\% Cl: 138-150) for the non-involvement group, 143 months (SE: 16.136, 95\% Cl: 112 175) for the metastatic group, and 88 months (SE: 12.017 , 95\% Cl:64-111) for the synchronous group (Fig. 1). In binary comparisons between the non-involvement and metastatic group ( $p=0.748$ ), between the non-involvement and synchronous group $(p=0.128)$ and between the synchronous group and the metastatic group ( $p=0.353)$, no significant difference was found in overall survival.

\section{DISCUSSION}

This study showed that $2.8 \%$ of low-risk endometrial cancer patients had ovarian metastasis and 3.3\% had synchronous ovarian involvement. These rates are similar to those of Stage I endometrial cancer [4-6], though higher than the metastasis rate previously reported for low-risk patients [2]. Most of the metastatic patients in our cohort were young and premenopausal. This finding is contradicted by earlier studies, which concluded that synchronous tumors were more likely to occur in younger, premenopausal patients $[4,13,14]$. In addition, this feature has often been used to explain why synchronous tumors have a more favorable

\begin{tabular}{|c|c|c|c|c|c|c|c|c|c|c|c|}
\hline $\begin{array}{l}\text { Patient } \\
\text { no. }\end{array}$ & Age & Menopause & Grade & $\begin{array}{l}\text { Diameter of } \\
\text { endometrial tumor } \\
{[\mathrm{cm}]}\end{array}$ & $\begin{array}{l}\text { Diameter of } \\
\text { ovarian tumor } \\
\text { [cm] }\end{array}$ & MSH2 & MSH6 & MLH1 & PMS2 & $\begin{array}{l}\text { Dead } \\
\text { or alive }\end{array}$ & $\begin{array}{c}\text { Survey } \\
\text { [month] }\end{array}$ \\
\hline 1 & 49 & pre & I & 1.5 & 2 & + & + & + & + & Alive & 91 \\
\hline 2 & 48 & post & II & 2 & 4 & + & + & - & - & Alive & 130 \\
\hline 3 & 49 & pre & I & 2.5 & MT & + & + & + & + & Alive & 101 \\
\hline 4 & 44 & pre & II & 3 & 3 & - & - & + & + & Alive & 96 \\
\hline 5 & 44 & pre & 1 & 1.5 & 3 & - & - & + & + & Alive & 15 \\
\hline 6 & 42 & pre & I & 2.5 & 8 & - & - & + & + & Alive & 19 \\
\hline 7 & 47 & pre & II & 3 & 1 & + & + & + & + & Alive & 161 \\
\hline 8 & 58 & post & II & 2 & 3 & + & + & - & - & Dead & 23 \\
\hline 9 & 49 & pre & II & 6 & MT & + & + & + & + & Alive & 109 \\
\hline 10 & 55 & post & II & 2 & 2.5 & + & + & - & - & Alive & 98 \\
\hline
\end{tabular}

MT - microscopic tumor 


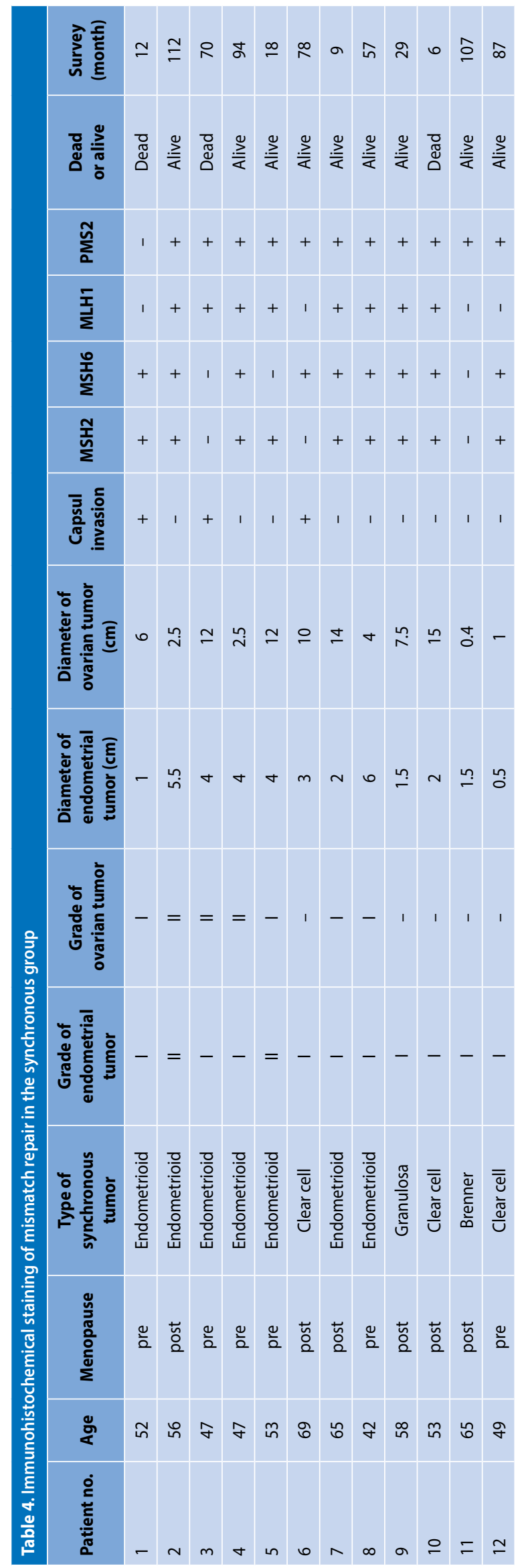

prognosis than metastatic tumors [15]. Böss et. al. [16], reported that patients with metastasis to the ovary tended to be younger than patients with synchronous tumors. Similarly, higher rates of ovarian metastasis were detected under the age of 40 when ovarian conservation was performed in early-stage endometrial cancer patients [17].

Well-characterized risk factors that may be responsible for ovarian involvement in endometrial cancer are myometrial invasion, higher tumor grade, and lymphovascular space invasion [5, 6]. Modaress et al. [18], showed a 66-fold increase in ovarian metastasis with myometrial invasion. In addition, serosal invasion, tubal involvement, and positive abdominal cytology emerged as independent risk factors in clinical stage I patients [6]. But there are not many studies examining ovarian involvement in low-risk patients where all these factors are the same-negative. In a study by Ignatov et al., they reported $0.5 \%$ rate of ovarian metastasis in low-risk patients, and they could not find a difference in overall survival with ovarian involvement [2].

The size of the endometrial tumor was similar between groups. Also, the diameter of the ovarian tumor was larger in the synchronous group, but the difference was not statistically significant. If the ovary was invaded by a synchronous tumor rather than metastasis, the diameter of the tumor would probably be larger [1, 4]. There were two patients with microscopic ovarian metastasis, and if these patients had not had an oophorectomy, the skipped occult metastasis could have resulted in reduced progression-free survival.

Although more lymphadenectomy was performed in the synchronous group, the total metastatic lymph node count was found to be greater in the metastatic group. Bese et al. [19], reported that performing lymphadenectomy was found to be a significant risk factor for recurrence in synchronous tumors. The larger ovarian mass in the synchronous group is associated with more lymph node resection and may be the cause of the good prognosis observed in this group. In all, 7/12 (58\%) of synchronous tumors had the same endometrioid histology. Soliman et al. [14], reported $68 \%$ concordant endometrioid adenocarcinoma and noted that the most favorable prognosis was associated with the same endometrioid histology. Young, premenopausal, overweight, and nulliparous women in this study had a median survival of 10 years and a good prognosis. Similarly, Chiang et al. [20], reported a survival of 63 months with the same histology and 48 months with a different histology in synchronous tumors.

In general, the prognosis in patients with synchronous ovarian involvement is better than in metastatic involvement [21]. In a gynecologic oncology group study, the reported five-year survival rates were higher ( $86 \%$ vs $58 \%$ ) with synchronous tumors [13]. Bese et al. [19], reported 


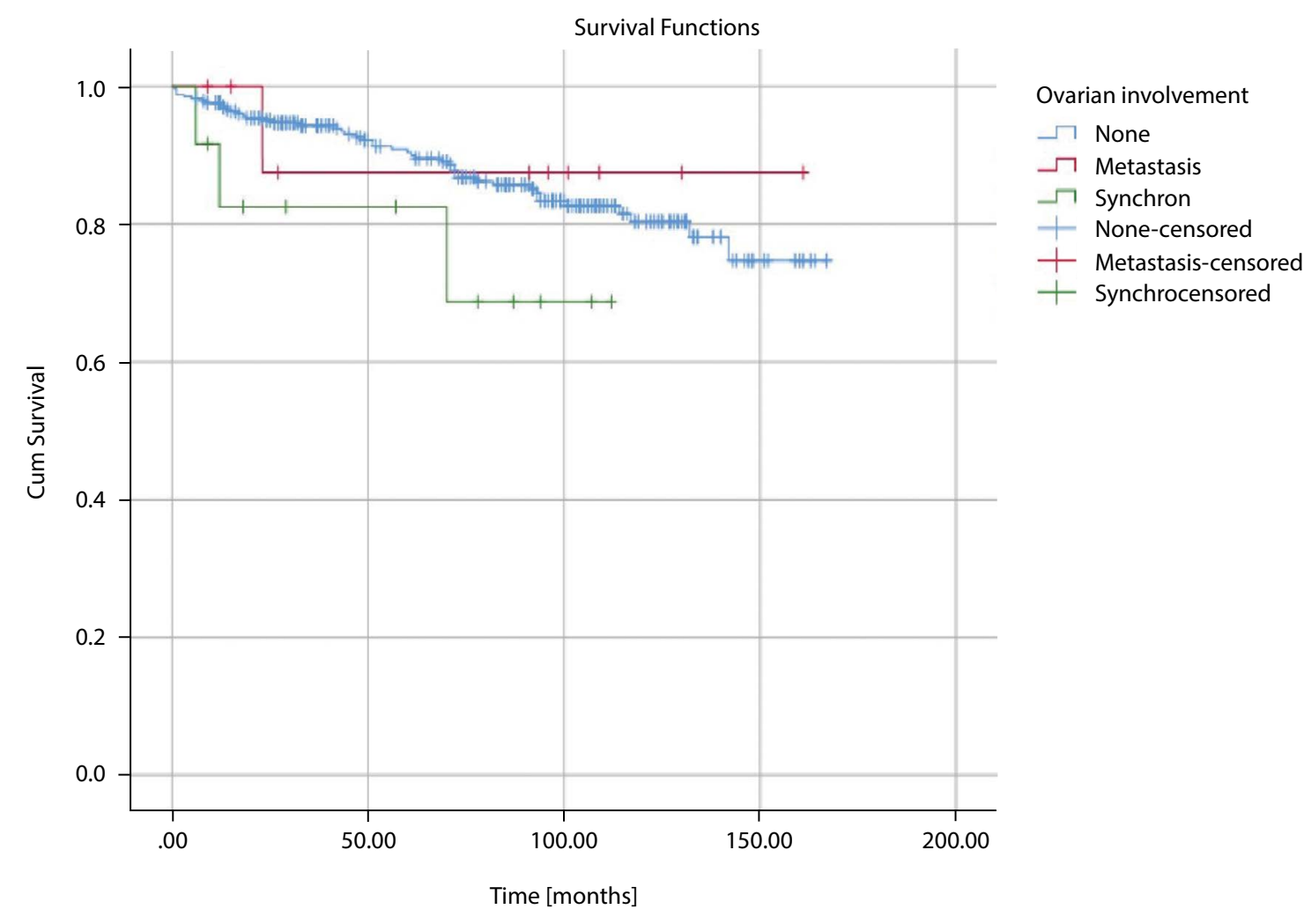

Figure 1. Overall survival analysis of patients

a dramatic change in 10-year survival rates of $61.3 \%$ and $36.6 \%$ in synchronous and metastatic groups, respectively. The critical point of this study was that only $25 \%$ of the study population consisted of Stage $\otimes$ patients. Simultaneously detected endometrial and ovarian carcinomas with a grade 1 tumor had a significantly lower five-year recurrence rate ( $8 \%$ vs $22.4 \%$ ) compared with patients with at least one tumor above grade 1 [13]. In the present study, no significant difference was detected in overall survival between three groups (no involvement, synchronous, or metastatic).

The presence of ovarian involvement elevates endometrial carcinoma to Stage IIla and assigns it to a high-risk category. However, the treatment options offered by institutions may vary, and the prognosis is therefore uncertain. Adjuvant therapy is often individualized based on stage, pathological outcomes, and risk factors. Some authors advocate not giving adjuvant chemotherapy or radiotherapy because of the lack of a statistically significant difference in overall survival in synchronous primary cancer patients [20]. However, Ayhan et al. [22], suggested adjuvant therapy in patients with advanced stages of ovarian cancer to improve survival. After adjusting risk factors such as stage, grade, and residual tumor tissue Heitz et al. [23], suggested chemother- apy for synchronous tumors and additional radiotherapy if the endometrial component is advanced.

MMR deficiency may be encountered in $20-40 \%$ of endometrial cancers and in $6.4 \%$ of ovarian cancers [24, 25]. Shikama et al., compared IHC results with clinicopathological findings of endometrium cancer. Patients with MMR proficiency were found to be significantly older, nulliparous, obese, and hypertensive compared to those with MMR deficiency. Overall survival was better in patients with MMR deficiency, but this was not significant [26]. Similarly in our study, MMR-deficient patients with ovarian involvement tended to be older and at higher grade. Clinicopathological features of 7054 patients diagnosed endometrial cancer with MMR deficiency were also evaluated in a systematic review [27]. Patients with MMR-deficient tumors were significantly younger, less likely to have grade I tumor, and had lower BMI.

MMR deficiency was reported $11 \%$ to $59 \%$ in synchronous tumors $[24,28]$. Previous studies have reported that MMR deficiency may be associated with optimal prognosis depending on low stage and grade in endometrial cancers $[29,30]$. However, studies in low-risk patients revealed that MMR-deficient tumors had worse progression-free survival 
and higher recurrence rates despite similar overall survival [31]. The reason for this condition is that most of these patients had not received adjuvant therapy, and MMR-deficiency can improve the response to treatment [32]. Conversely, in high-intermediate-risk patients, the recurrence rate of endometrial cancer for women with MMR deficiency was significantly higher regardless of adjuvant therapy [33]. In a study by Yoneoka et al. [34], MMR deficiency was observed in $28.3 \%$, MMR expression status was the same for endometrial and ovarian tumors, and no survival advantage was reported. We also found similar MMR expression status and survival between metastatic and synchronous groups.

Recently, a new generation of sequencing (NGS) technology has been used to explain the clonal relationship between endometrial cancer and ovarian cancer. It has been revealed that $95 \%$ of synchronous tumors clinically diagnosed as double primary cancers are actually clonal tumors [11, 12]. This means that simultaneous endometrial and ovarian tumors are not independent primary tumors. Despite the clonality, some authors hypothesize indolent spread phenomena instead of a'fully' metastatic disease [35]. One possible explanation is that these cells cannot spread to distant areas through the bloodstream, but spread transtubally to nearby areas, such as the ovary, and perform pseudometastase [27]. This theory can also help us understand why patients with these tumors often paradoxically exhibit good clinical outcomes.

The limitation of this study is that it was conducted in a single institution and used a retrospective study design. Another limitation is that disease-free survival was not accepted as a primary outcome; rather, the more precise overall survival was used. It is certain that multicentric studies involving greater numbers of patients are needed.

\section{CONCLUSIONS}

We found that ovarian involvement in low-risk endometrial cancer is rare, with a similar frequency to those previously reported in the literature. Younger age and premenopausal status were risk factors associated with ovarian metastasis. The probability of postmenopausal patients being in the synchronous group was lower than that of premenopausal patients. Overall survival did not show differences between all groups, and MMR-deficiency was similar between metastatic and synchronous groups.

\section{Acknowledgments}

The authors wish to thank Aysel Gezer for her contribution to survival analysis.

\section{Conflict of interests}

The authors have no conflict of interest to disclose.

\section{REFERENCES}

1. Lin $K Y$, Miller DS, Bailey $A A$, et al. Ovarian involvement in endometrioid adenocarcinoma of uterus. Gynecol Oncol. 2015; 138(3): 532-535, doi: 10.1016/j.ygyno.2015.07.012, indexed in Pubmed: 26186908.

2. Ignatov $T$, Eggemann $H$, Burger $E$, et al. Ovarian metastasis in patients with endometrial cancer: risk factors and impact on survival. J Cancer Res Clin Oncol. 2018; 144(6): 1103-1107, doi: 10.1007/s00432-018-2628-2, indexed in Pubmed: 29541859.

3. AlHilli MM, Dowdy SC, Weaver AL, et al. Incidence and factors associated with synchronous ovarian and endometrial cancer: a population-based case-control study. Gynecol Oncol. 2012; 125(1): 109-113, doi: 10.1016/j. ygyno.2011.12.444, indexed in Pubmed: 22210467.

4. Walsh C, Holschneider C, Hoang Y, et al. Coexisting ovarian malignancy in young women with endometrial cancer. Obstet Gynecol. 2005; 106(4): 693-699, doi: 10.1097/01.AOG.0000172423.64995.6f, indexed in Pubmed: 16199623.

5. Gemer O, Bergman M, Segal S. Ovarian metastasis in women with clinical stage I endometrial carcinoma. Acta Obstet Gynecol Scand. 2004; 83(2): 208-210, doi: 10.1111/j.0001-6349.2004.00408.x, indexed in Pubmed: 14756742

6. Akbayır $\mathrm{O}$, Kuru $\mathrm{O}$, Goksedef $\mathrm{P}$, et al. Coexisting ovarian malignancy in patients with clinical stage I endometrial carcinoma. Arch Gynecol Obstet. 2012; 286(5): 1241-1245, doi: 10.1007/s00404-012-2402-7, indexed in Pubmed: 22688443.

7. Soliman PT, Broaddus RR, Schmeler KM, et al. Women with synchronous primary cancers of the endometrium and ovary: do they have Lynch syndrome? J Clin Oncol. 2005; 23(36): 9344-9350, doi: 10.1200/JCO.2005.03.5915, indexed in Pubmed: 16361634.

8. Ramus SJ, Elmasry K, Luo Z, et al. Predicting clinical outcome in patients diagnosed with synchronous ovarian and endometrial cancer. Clin Cancer Res. 2008; 14(18): 5840-5848, doi: 10.1158/1078-0432.CCR-08-0373, indexed in Pubmed: 18794095.

9. Batte BAL, Bruegl AS, Daniels MS, et al. Consequences of universal $\mathrm{MSI} / \mathrm{IHC}$ in screening ENDOMETRIAL cancer patients for Lynch syndrome. Gynecol Oncol. 2014; 134(2): 319-325, doi: 10.1016/j.ygyno.2014.06.009, indexed in Pubmed: 24933100.

10. Schultheis AM, $\mathrm{Ng} C K Y$, De Filippo MR, et al. Massively Parallel Sequencing-Based Clonality Analysis of Synchronous Endometrioid Endometrial and Ovarian Carcinomas. J Natl Cancer Inst. 2016; 108(6): djv427, doi: 10.1093/jnci/djv427, indexed in Pubmed: 26832770.

11. Anglesio MS, Wang YiK, Maassen M, et al. Synchronous Endometrial and Ovarian Carcinomas: Evidence of Clonality. J Natl Cancer Inst. 2016; 108(6): djv428, doi: 10.1093/jnci/djv428, indexed in Pubmed: 26832771.

12. Scully RE, Young RH, Clement PB. Tumors of the Ovary, Maldeveloped Gonads, Fallopian Tube, and Broad Ligament. Armed Forces Institute of Pathology, Washington 1998.

13. Zaino R, Whitney C, Brady MF, et al. Simultaneously detected endometrial and ovarian carcinomas--a prospective clinicopathologic study of 74 cases: a gynecologic oncology group study. Gynecol Oncol. 2001; 83(2): 355-362, doi: 10.1006/gyno.2001.6400, indexed in Pubmed: 11606097.

14. Soliman PT, Slomovitz BM, Broaddus RR, et al. Synchronous primary cancers of the endometrium and ovary: a single institution review of 84 cases. Gynecol Oncol. 2004; 94(2): 456-462, doi: 10.1016/j. ygyno.2004.05.006, indexed in Pubmed: 15297188.

15. Oranratanaphan S, Manchana T, Sirisabya N. Clinicopathologic variables and survival comparison of patients with synchronous endometrial and ovarian cancers versus primary endometrial cancer with ovarian metastasis. Asian Pac J Cancer Prev. 2008; 9(3): 403-407, indexed in Pubmed: 18990010.

16. Juhasz-Böss I, Fehm T, Becker S, et al. Endometrial Cancer: Comparison of Patients with Synchronous Primary Carcinoma of the Endometrium and Ovary vs Endometrial Carcinoma with Ovarian Metastases. Geburtshilfe Frauenheilkd. 2012; 72(8): 721-726, doi: 10.1055/s-0032-1315206, indexed in Pubmed: 25258464.

17. Matsuo K, Machida H, Stone RL, et al. Risk of Subsequent Ovarian Cancer After Ovarian Conservation in Young Women With Stage I Endometrioid Endometrial Cancer. Obstet Gynecol. 2017; 130(2): 403-410, doi: 10.1097/AOG.0000000000002142, indexed in Pubmed: 28697110.

18. Modaress MG, Cheraghi F, Zamani N. Ovarian metastasis in endometriod type endometrial cancer. Int J Fertil Steril. 2011; 5(3): 148-151.

19. Bese T, Sal V, Kahramanoglu I, et al. Synchronous Primary Cancers of the Endometrium and Ovary With the Same Histopathologic Type Versus Endometrial Cancer With Ovarian Metastasis: A Single Institu- 
tion Review of 72 Cases. Int J Gynecol Cancer. 2016; 26(2): 394-406, doi: 10.1097/IGC.0000000000000600, indexed in Pubmed: 26588233.

20. Chiang YC, Chen CA, Huang CY, et al. Synchronous primary cancers of the endometrium and ovary. Int J Gynecol Cancer. 2008; 18(1): 159-164, doi: 10.1111/j.1525-1438.2007.00975.x, indexed in Pubmed: 17506847.

21. Williams MG, Bandera EV, Demissie K, et al. Synchronous primary ovarian and endometrial cancers: a population-based assessment of survival. Obstet Gynecol. 2009; 113(4): 783-789, doi: 10.1097/AOG.0b013e31819c7bdf, indexed in Pubmed: 19305320.

22. Ayhan A, Guvenal T, Coskun F, et al. Survival and prognostic factors in patients with synchronous ovarian and endometrial cancers and endometrial cancers metastatic to the ovaries. Eur J Gynaecol Oncol. 2003; 24(2): 171-174, indexed in Pubmed: 12701972.

23. Heitz F, Amant F, Fotopoulou $C$, et al. Synchronous ovarian and endometrial cancer--an international multicenter case-control study. Int J Gynecol Cancer. 2014; 24(1): 54-60, doi: 10.1097/IGC.0000000000000019, indexed in Pubmed: 24300466.

24. Reijnen C, Küsters-Vandevelde HVN, Ligtenberg MJL, et al. Molecular profiling identifies synchronous endometrial and ovarian cancers as metastatic endometrial cancer with favorable clinical outcome. Int J Cancer. 2020; 147(2): 478-489, doi: 10.1002/ijc.32907, indexed in Pubmed: 32022266.

25. Murphy MA, Wentzensen N. Frequency of mismatch repair deficiency in ovarian cancer: a systematic review This article is a US Government work and, as such, is in the public domain of the United States of America. Int J Cancer. 2011; 129(8): 1914-1922, doi: 10.1002/ijc.25835, indexed in Pubmed: 21140452.

26. Shikama A, Minaguchi T, Matsumoto $\mathrm{K}$, et al. Clinicopathologic implications of DNA mismatch repair status in endometrial carcinomas. Gynecol Oncol. 2016; 140(2): 226-233, doi: 10.1016/j.ygyno.2015.11.032, indexed in Pubmed: 26644264

27. Gordhandas S, Kahn RM, Gamble C, et al. Clinicopathologic features of endometrial cancer with mismatch repair deficiency. Ecancermedicalscience. 2020; 14: 1061, doi: 10.3332/ecancer.2020.1061, indexed in Pubmed: 32582376.
28. Kobayashi $Y$, Nakamura K, Nomura H, et al. Clinicopathologic analysis with immunohistochemistry for DNA mismatch repair protein expression in synchronous primary endometrial and ovarian cancers. Int J Gynecol Cancer. 2015; 25(3): 440-446, doi: 10.1097/IGC.0000000000000377, indexed in Pubmed: 25695547.

29. Aysal A, Karnezis A, Medhi l, et al. Ovarian endometrioid adenocarcinoma: incidence and clinical significance of the morphologic and immunohistochemical markers of mismatch repair protein defects and tumor microsatellite instability. Am J Surg Pathol. 2012; 36(2): 163-172, doi: 10.1097/PAS.0b013e31823bc434, indexed in Pubmed: 22189970.

30. McConechy MK, Talhouk A, Li-Chang HH, et al. Detection of DNA mismatch repair (MMR) deficiencies by immunohistochemistry can effectively diagnose the microsatellite instability (MSI) phenotype in endometrial carcinomas. Gynecol Oncol. 2015; 137(2): 306-310, doi: 10.1016/j.ygyno.2015.01.541, indexed in Pubmed: 25636458.

31. Kim SR, Pina A, Albert A, et al. Mismatch repair deficiency and prognostic significance in patients with low-risk endometrioid endometrial cancers. Int J Gynecol Cancer. 2020; 30(6): 783-788, doi: 10.1136/ijgc2019-000910, indexed in Pubmed: 32354793.

32. Kim SR, Pina A, Albert A, et al. Does MMR status in endometrial cancer influence response to adjuvant therapy? Gynecol Oncol. 2018; 151(1): 76-81, doi: 10.1016/j.ygyno.2018.08.020, indexed in Pubmed: 30172479.

33. Backes FJ, Haag J, Cosgrove CM, et al. Mismatch repair deficiency identifies patients with high-intermediate-risk (HIR) endometrioid endometrial cancer at the highest risk of recurrence: A prognostic biomarker. Cancer. 2019; 125(3): 398-405, doi: 10.1002/cncr.31901, indexed in Pubmed: 30561762.

34. Yoneoka $\mathrm{Y}$, Yoshida $\mathrm{H}$, Ishikawa $\mathrm{M}$, et al. Prognostic factors of synchronous endometrial and ovarian endometrioid carcinoma. J Gynecol Oncol. 2019; 30(1): e7, doi: 10.3802/jgo.2019.30.e7, indexed in Pubmed: 30479091.

35. Hájková N, Tichá l, Hojný J, et al. Synchronous endometrioid endometrial and ovarian carcinomas are biologically related: A clinico-pathological and molecular (next generation sequencing) study of 22 cases. Oncol Lett. 2019; 17(2): 2207-2214, doi: 10.3892/ol.2018.9855, indexed in Pubmed: 30675285. 